Article

\title{
Effect of Stored Humidity and Initial Moisture Content on the Qualities and Mycotoxin Levels of Maize Germ and Its Processing Products
}

\author{
Yun-qi Wen ${ }^{\dagger}$, Li-li $\mathrm{Xu}^{\dagger}{ }^{\dagger}$, Chang-hu Xue and Xiao-ming Jiang *(D) \\ College of Food Science and Engineering, Ocean University of China, No.5, Yushan Road, Qingdao, \\ Shandong Province 266003, China; wenyq0715@163.com (Y.-q.W.); xulili8339@163.com (L.-1.X.); \\ oucxuech@163.com (C.-h.X.) \\ * Correspondence: jxm@ouc.edu.cn; Tel.: +86-13-045-022-337 \\ + These authors contributed equally to this study.
}

Received: 21 July 2020; Accepted: 18 August 2020; Published: 20 August 2020

check for updates

\begin{abstract}
With high fat and protein content, maize germ is easily infected with fungus and mycotoxins during its storage. The qualities and safety of germ and its processing products may be affected by the storage. However, studies on the effect of storage on quality and polluted mycotoxin level of maize germ are limited. In this study, maize germ was stored with different initial moisture contents $(5.03,9.07,11.82$ and $17.97 \%)$ or at different relative humidity $(75,85$ and $95 \%)$ for 30 days. The quality indices of germ (moisture content and crude fat content) and their produced germ oils (color, acid value and peroxide value) as well as the zearalenone (ZEN) and deoxynivalenol (DON) levels of germ, oils and meals were analyzed. Results showed that maize germ with high initial moisture contents $(11.82,17.97 \%)$ or kept at high humidity (95\%) became badly moldy at the end of storage. Meanwhile, the qualities of these germ and oils showed great changes. However, the ZEN and DON contents of this maize germ, oils and meals stayed at similar levels $(p<0.05)$. Therefore, the storage could produce influence on the qualities of germ and oils, but showed limited effect on the DON and ZEN levels of germ and their processing products. According to this study, the storage condition of germ with no more than $9 \%$ moisture content and no higher than $75 \%$ humidity was recommended. This study would be benefit for the control of germ qualities and safety during its storage.
\end{abstract}

Keywords: maize germ; zearalenone; deoxynivalenol; storage; maize germ oil; maize germ meal

Key Contribution: (1). Qualities of maize germ stored with initial moisture contents (11.82, 17.97\%) or kept at humidity (95\%), and its corresponding oils showed great changes; (2). ZEN and DON contents of maize germ, oils and meals stayed at similar levels during the storage; (3). Storage condition of germ with no more than $9 \%$ moisture content and no higher than $75 \%$ humidity was recommended.

\section{Introduction}

Consisting of endosperm and germ, corn is a main economic crop in the world [1]. At the same time, maize germ is a corn-processing byproduct, with high fat content (35-47\%). It is also rich in various nutritional compositions, such as vitamin E and polyunsaturated fatty acids [2]. Maize germ is a good source of edible oil which is highly consumed around the world for its unique flavor [3]. Nowadays, large quantities of corn are used for producing alcohol and fuel alcohol, resulting in the production of large quantities of maize germ [4]. Maize germ is also used as an initial raw material to feed livestock such as swine, which are susceptible to the toxic effect of mycotoxins $[5,6]$. However, because of the high fat and protein content of maize germ, maize germ is more easily attacked by 
fungus and polluted with mycotoxins than corn and wheat, etc.- especially under the condition of appropriate temperature and humidity [7]. The growth and metabolism of mold not only leads to the bad organoleptic qualities of corn and germ, but also to the production of a range of mycotoxins, such as zearalenone (ZEN) and deoxynivalenol (DON).

Zearalenone (ZEN) is usually produced by Fusarium species, including Fusarium graminearum, Fusarium culmorum, Fusarium cerealis and Fusarium equiseti, while DON can be produced by Fusarium graminearum and Fusarium culmorum. The molecular structures of ZEN and DON are shown in Figure 1. They are both considered as the most frequently detected mycotoxins in cereal and its byproducts, and they can pose heavy health risks for human beings as well as animals [8-10]. ZEN has been demonstrated to be estrogenic, hepatotoxic, immunotoxic and carcinogenic. DON has been shown to be acute or chronically poisonousness and exhibits carcinogenic, teratogenic and mutagenic characters [3,11]. Therefore, maximum permissible levels of ZEN and DON in foods have been established by many countries and organizations. The level of ZEN in corn oil must not exceed $400 \mu \mathrm{g} / \mathrm{kg}$; levels of DON content in cereals intended for human direct consumption, cereal flour, bran and germ must not exceed $750 \mu \mathrm{g} / \mathrm{kg}$ [12].

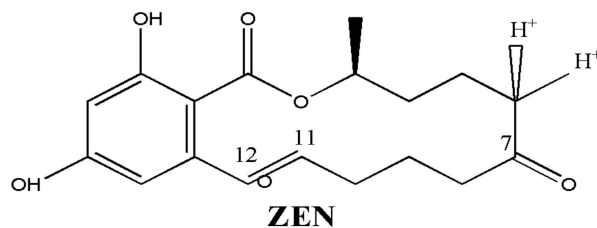

ZEN

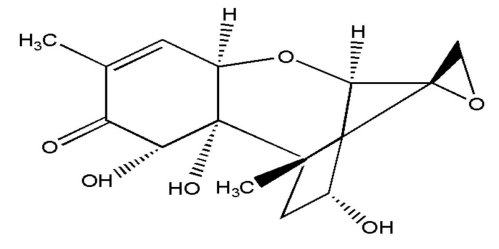

DON

Figure 1. Molecular structures of zearalenone (ZEN) and deoxynivalenol (DON).

Several food samples-including fiber-enriched bread, bran-enriched bread, cornflakes, popcorn and oatmeal—collected from Belgian supermarkets during April 2010 to October 2011 were detected to contain mycotoxins. The results show that all of these foods contaminated with an average of two to six mycotoxins. Maize and its byproducts were mostly infected with DON, ZEN and derivatives [13]. Another study reports that corn and its six derived milling fractions, including germ, bran, large and small grits, flour and animal feed flour, are all contaminated by mycotoxins. In particular, germ, bran and animal feed flour show marked concentration factors [14]. In terms of the distribution of DON in whole corn and milled corn fractions, endosperm, germ and pericarp contains 20, 25 and 55\% of the original DON of kernel, respectively [15]. Meanwhile, ZEN is reported to be evenly distributed during the milling process in all corn byproducts except corn starch [16]. It is notable that the most obvious ZEN and DON contaminations occur during the period of preharvest crops. There is also a possibility that mycotoxins could pollute cereal in postharvest crops $[17,18]$. When moldy corn or germ is used as raw materials for the production of processing products (such as maize germ oil and maize germ meal), pigments, mycotoxins, etc., produced by mold may migrate into the processing products, which may lead the poor qualities of the processing products. Thus, moldy corn or germ may lead to a decrease in the economic value of processing products, as well as edible safety for humans and animals. Nowadays, large quantities of maize germ obtained from corn deep processing is usually sold to maize germ oil production enterprises. Maize germ is usually stored for a period of time before processing. However, there are few reports showing the influence of storage with different condition (initial moisture content, temperature and relative humidity) on the qualities and mycotoxins contaminated levels of maize germ, as well as the corresponding maize germ oil and maize germ meal.

Therefore, this study is aimed to investigate the influence of moisture content and humidity on the qualities and ZEN and DON levels of maize germ and its maize germ oil and meal during maize germ storage. The quality indices of maize germ (moisture content and crude fat content) and maize germ oil (color, acid value and peroxide value) were analyzed. Meanwhile, mycotoxin contamination levels 
(ZEN and DON) of maize germ and maize germ oil-as well as maize germ meal—were determined. This study would be helpful for the maize-germ processing industry to build reasonable storage conditions of maize germ for reducing the adverse effect of ZEN and DON on maize germ and its processing products.

\section{Results and Discussion}

\subsection{Quality Changes of Maize Germ During Storage}

Maize germ with different initial moisture contents $(5.03,9.07,11.82$ and 17.97\%) was stored at the situation of $25{ }^{\circ} \mathrm{C}$ (temperature)/45\% (humidity) for 30 days, while other maize germ with $9.07 \%$ initial moisture content was stored at the conditions of $25^{\circ} \mathrm{C}$ and different humidity $(75,85$ and $95 \%)$ for 30 days. The appearance changes of the maize germ were photographed (Figures S1 and S2). The changes of moisture contents and crude fat contents of these stored maize germ samples are shown in Figure 2A,B.
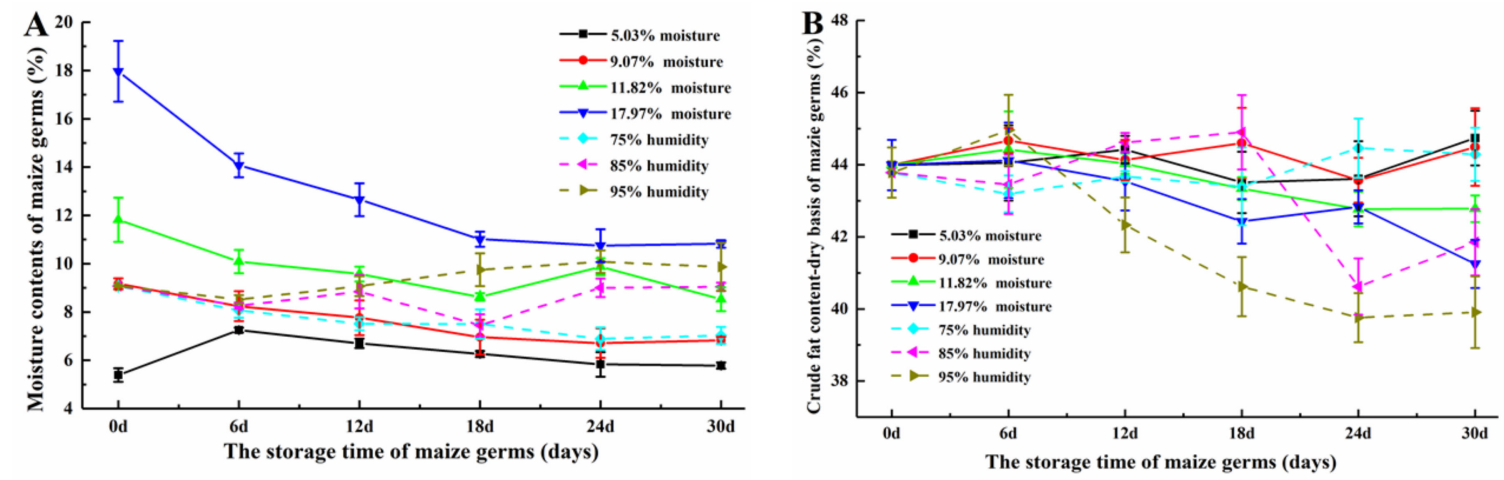

Figure 2. (A) Moisture contents and (B) crude fat contents of maize germ during storage.

Moisture content and crude fat content of maize germ are two important indexes in reflecting the quality of maize germ. As shown in Figure 2A, the moisture content of germ samples with initial moisture contents of $9.07,11.82$ and $17.97 \%$, respectively, showed similar changing trends during storage at $25{ }^{\circ} \mathrm{C}$ and relative humidity of $45 \%$. Their moisture contents all tended to decline over time, which reduced to $6.83(p<0.05), 8.53(p<0.05)$ and 10.82\% $(p<0.05)$, respectively. The moisture content of the sample with $5.03 \%$ initial moisture content remained almost the same $(p>0.05)$ during storage. The probable reason for this phenomenon may be related to the storage containers and humidity. The raw maize germ materials were stored in open plastic bottle containers and kept under low relative humidity. The germ in the upper position of container was easily desorbed of water, which made the samples with higher moisture contents lose water. Also, it was noticed that the moldy germ was mainly found in the middle and bottom part of the container. As the germ was stored at different humidity, the moisture contents of maize germ showed different changing trends. When the humidity was kept at $75 \%$, the moisture content of germ reduced from 9.07 to $7.03 \%(p<0.05)$. However, the germ kept at 85 and 95\% humidity exhibited the high final moisture content at $9.04(p>0.05)$ and 9.87\% $(p>0.05)$, respectively. In the industrial production and utilization of corn germ, the moisture content of corn germ is usually determined according to the requirement of processing technology. Therefore, the moisture content of corn germ is various aiming for different applications, which could range from 3 to $13 \%$ [19-22].

As shown in Figure 2B, the crude fat content of maize germ with initial lower moisture contents (5.03 and 9.07\%) showed small changes (fluctuating around 44\%, $p>0.05$ ) during storage. Meanwhile, the crude fat contents of germ with higher moisture contents (11.82 and 17.97\%) was gradually declined during the storage, which decreased to $42.78 \%(p>0.05)$ and $41.25 \%(p<0.05)$, respectively. Germ (initial moisture content, 9.07\%) kept at a lower relative humidity (75\%) condition showed similar 
crude fat content during the storage. The crude fat contents of germ kept at higher relative humidity (85 and 95\%) conditions declined by 1.93 and 3.87\%, respectively, which was finally decreased to the contents of $41.85(p<0.05)$ and 39.91\% $(p<0.05)$, respectively. It was speculated that maize germ was prone to occur with moldy situation under the condition of relative high humidity and the crude fat content of germ would decline, resulting in the economic losses. It was seen that germ with lower initial moisture contents (5.03 and 9.07\%) as well as kept in lower relative humidity (45 and 75\%) did not show mold pollution or had slight moldy kernels during the entire 30-day storage period. However, germ with higher moisture contents (11.82 and 17.97\%) or kept in relative higher humidity (85 and 95\%) occurred with severe moldy phenomenon at 18th day. The growth and reproduction of mold could resolve a certain amount of fat, which produce substances such as free fatty acids and also lead the decrease of the crude fat content of maize germ [23]. Although the crude fat is decomposed to a certain extent, corn germ still has high fat content. Corn germ is rich in oil and the oil contents range from 35 to $56 \%$ [22]. The effect of different corn degerming and fermentation treatments on the germ yields and oil contents was studied; the results showed that the oil contents in germ ranged from 33.50 to $39.16 \%$ [24].

\subsection{Quality Changes of Maize Germ Oils During Storage}

Maize germ taken from different storage periods $(0,6,12,18,24$ and 30 days) was used for the solvent extraction to obtain maize germ oils. The quality indices of maize germ oils-including color, acid value and peroxide value-were analyzed (Figure 3A-C). As shown in Figure 3A, the colors of maize germ oils extracted from the germ from different storage periods and with lower initial moisture contents (5.03 and 9.07\%) showed no significant differences $(p>0.05)$. On the other hand, the stored germ with a higher initial moisture content (11.82 and $17.92 \%)$ could produce deep color in oils, and the red values of these corn germ oils, respectively reached $8.7(p<0.05)$ and $11.0(p<0.05)$ (yellow value was set as 30) over 24 days of storage. Therefore, there may be a positive correlation between the color of the maize germ oil and the degree of germ moldiness. This is to say that germ with lower initial moisture content exhibited no obvious mold changes and the corresponding oils extracted from them showed light color, while the germ with higher initial moisture content occurred with moldy damage and the corresponding oils showed deep color. In comparing the colors of corn germ oils obtained from the germ stored in different humidity $(75,85$ and 95\%), it was found that the higher the humidity during germ storage, the higher the degree of moldiness-resulting in a darker color of the corresponding germ oil. Interesting, the red values of corn germ oils (including these oils extracted from the germ with higher initial moisture contents (11.82 and 17.92\%) or the germ stored at higher relativity humidity (95\%)) appeared slight declined at the end of storage (30 d), which may have a relationship with the growth and reproduction of different mold species at the later period of storage.

The acidity of the germ oils can also change dramatically during storage (Figure 3B). It was seen that the acid values of oils derived from germ with lower initial moisture contents (5.03 and 9.07\%) or stored at lower relative humidity (75\%) condition stayed in a similar value during the storage $(p>0.05)$, while these oils from germ with higher initial moisture contents (11.82 and $17.92 \%)$ or stored at higher relative humidity (85 and 95\%) conditions showed the $4-9$ times fold $(p<0.05)$ increase of acid values $(20.14,43.22,25.86$ and $42.98 \mathrm{mg} \mathrm{KOH} / \mathrm{g}$, respectively). It was suspected that an improper storage condition for maize germ can lead the deterioration of germ oil quality. On one hand, under the action of lipase, the lipid in maize germ was hydrolyzed, leading the production of free fatty acids [25]. On the other hand, the growth of mold may use and break lipids down-also leading to produce free fatty acids. The storage condition with high humidity and moisture content was beneficial for the growth of mold. It could increase the breathing intensity of mold and then produce more heat and finally improve the stored temperature of germ. This situation was more conducive to increasing lipase activity and mold growth rate. Finally, more lipid was decomposed, leading to the production of more free fatty acids. Therefore, it was necessary to control the moisture content of germ and the storage humidity to obtain high quality of maize germ oil. Additionally, the peroxide values of maize germ oils 
are shown in Figure 3C. It was found that the peroxide values of oils obtained from germ with initial moisture contents $(5.03,9.07$ and $11.82 \%)$ or stored at relative humidity $(75$ and $85 \%)$ stayed at a similar level $(p>0.05)$. Those oils from germ with $17.92 \%$ of initial moisture content or stored at $95 \%$ of relative humidity showed a decline of peroxide values $(p<0.05)$. A possible reason for the phenomenon may be related to the blocking effect of water on the lipid oxidation [26]. The quality of corn germ oil is affected by the method of oil extraction, corn germ quality, etc. The effect of moisture and heat treatment of corn germ on oil quality was studied, results showing that increasing the moisture contents of the corn germ from 8 to $25 \%$ before oil extraction increased the acid values (3.02-4.01 mg KOH/g), peroxide values (1.04-2.10 $\mathrm{mmol} / \mathrm{kg}$ ) and the red values (7.3-8.7) [27]. An efficient and eco-friendly extraction of corn germ oil was adopted. The obtained crude germ oil showed the acid value with $0.77 \mathrm{mg} \mathrm{KOH} / \mathrm{g}$ and peroxide value with $10.16 \mathrm{mmol} / \mathrm{kg}$ [22]. Another study showed the corn germ oil with a high acid value $(10.7 \mathrm{mg} \mathrm{KOH} / \mathrm{g})$, which was extracted by Soxhlet extraction using hexane [28].
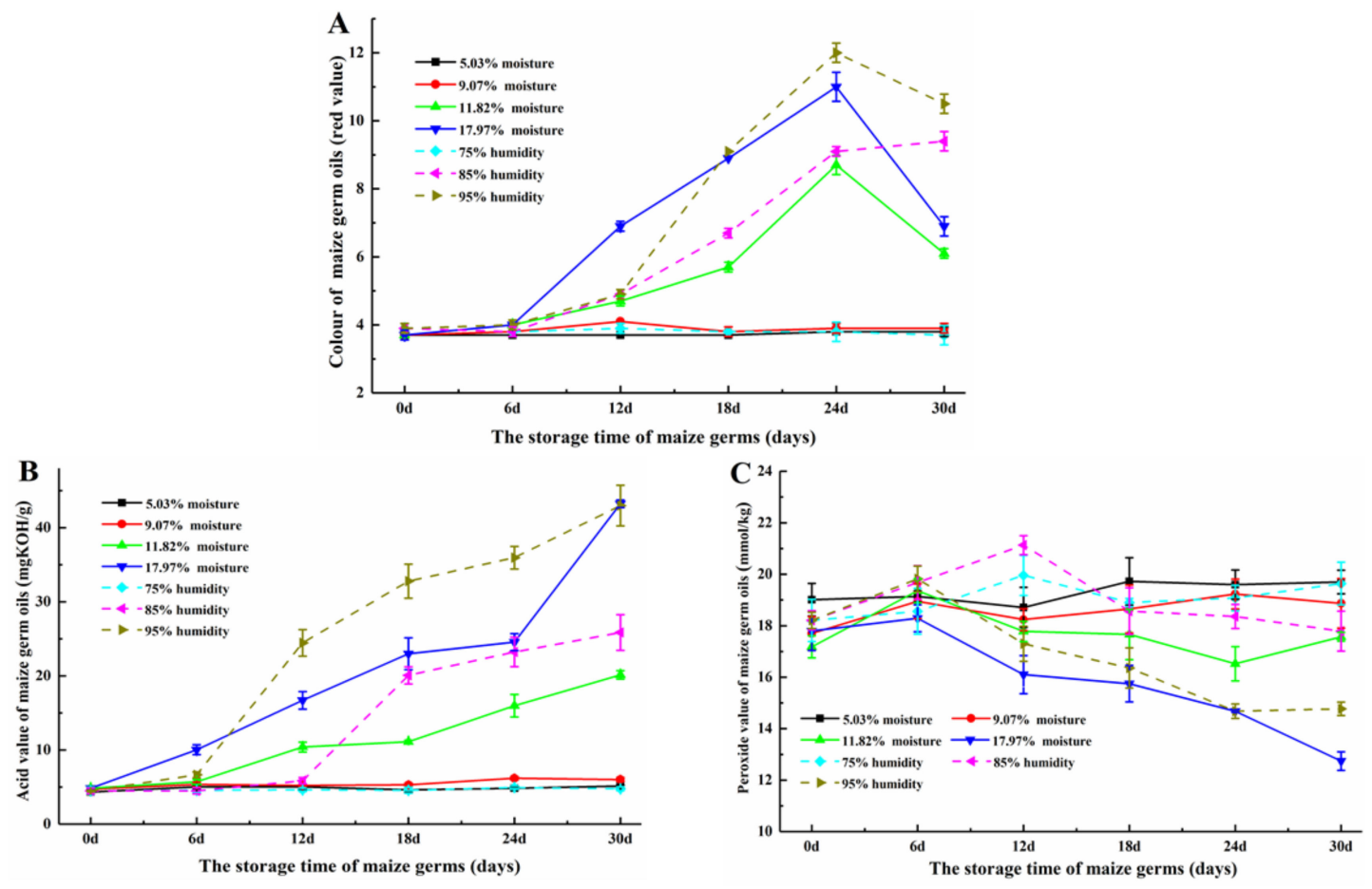

Figure 3. (A) colors, (B) acid values and (C) peroxide values of maize germ oils extracted from germ from different storage stages.

\subsection{ZEN and DON Levels in Stored Maize Germ and Its Processing Products}

\subsubsection{ZEN and DON Levels in Stored Maize Germ}

Figure $4 \mathrm{~A}$ shows the ZEN contents of the maize germ from different storage period. The ZEN contents of all maize germ with different storage condition presented little changes during the storage $(p>0.05)$. The ZEN levels of germ with different initial moisture contents and stored under different humidity ranged from $972.44-1335.58 \mu \mathrm{g} / \mathrm{kg}$ and $973.32-1183.16 \mu \mathrm{g} / \mathrm{kg}$, respectively. However, the average contaminated level of ZEN was 1059.91 and $1092.56 \mu \mathrm{g} / \mathrm{kg}$, respectively. The DON contents of all maize germ are shown in Figure 4B. With different initial moisture contents $(5.03,9.07,11.82$ and $17.97 \%$ ), the DON levels of germ remained almost the same during the first 18 days of storage $(p>0.05)$. Then, the DON contents of these four samples, respectively increased to $345.6,420.1,489.5$ and $457.9 \mu \mathrm{g} / \mathrm{kg}$ at 24 th day storage. However, the DON contents of these four samples, respectively declined to $187.2,180.4,171.6$ and $160.9 \mu \mathrm{g} / \mathrm{kg}$ (all $p$-values of these contents were greater than 0.05 when compared with that of 0 th day storage) at 30th day storage. When maize germ was stored in 
different humidity $(75,85$ and $95 \%)$, the DON levels of maize germ showed the similar change trends $(p>0.05)$. The DON contents increased at both the 12th day $(473.3,275.3$ and $390.4 \mu \mathrm{g} / \mathrm{kg}$ ) and 24th day $(247.8,398.7$ and $484.7 \mu \mathrm{g} / \mathrm{kg})$ and then declined to $157.1,195.8$ and $148.3 \mu \mathrm{g} / \mathrm{kg}$ at the 30th day.
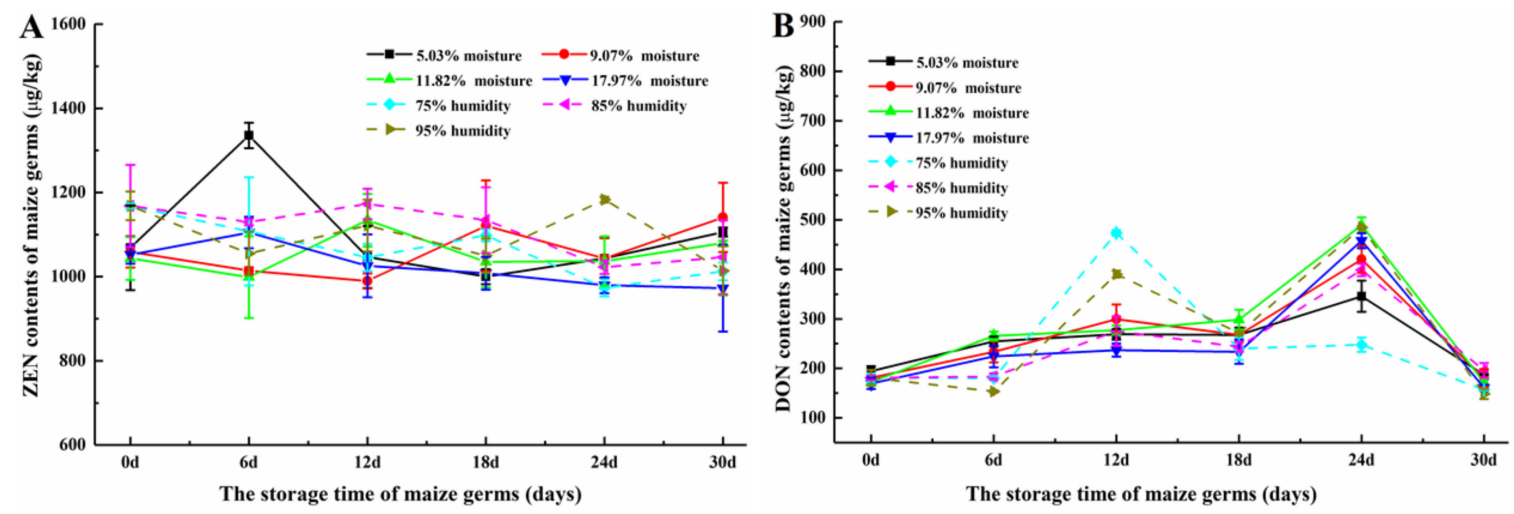

Figure 4. (A) ZEN contents and (B) DON contents of maize germ during the storage.

ZEN and DON are secondary metabolites of food spoilage fungi mainly produced by Fusarium. ZEN is commonly produced by Fusarium roseum and Fusarium moniliforme, and DON is produced by Fusarium graminearum and Fusarium culmorum. During the later storage, quantities of turquoise molds as well as part yellow and black molds grew on the corn germ. As reported, Fusarium toxin could occurred in all stored corn in Nigeria and the toxin concentrations showed the range of 11-479 $\mu \mathrm{g} / \mathrm{kg}$ [29]. The moisture content of the stored maize could also influence the activities of insect pests, which may also be relationship with mycotoxin levels $[17,30]$. For in-field contaminated cereals, a very significant correlation of DON with regions and meteorological factors (air temperature, precipitation, relative humidity) has been reported [31]. In corn, ZEN and DON may cooccur in preharvest and postharvest and could also increase during storage [32]. In actual processing and transportation, the mycotoxins contamination was a high risk for maize and its byproducts because of the high moisture content and high temperature caused by rain, humidity, etc. [1]. Therefore, in order to control the quality of stored maize germ, the transportation and storage environment of corn germ should be control and ZEN and DON contamination should be monitored.

\subsubsection{ZEN and DON Levels in Maize Germ Meals and Maize Germ Oils}

Maize germ with different initial moisture contents and stored under different humidity were further processed to obtain maize germ meals and maize germ oils. The contents of ZEN and DON contaminations in those processing products are shown in Figures 5 and 6. As shown in Figure 5A, ZEN contents of meals obtained from germ with different initial moisture contents and stored under different humidity ranged from 793.28 to $1198.73 \mu \mathrm{g} / \mathrm{kg}$ and from 829.41 to $1073.28 \mu \mathrm{g} / \mathrm{kg}$, respectively. The average ZEN content was 917.27 and $967.92 \mu \mathrm{g} / \mathrm{kg}$, respectively. Meanwhile, the DON contents of meals ranged from 200.2 to $329.5 \mu \mathrm{g} / \mathrm{kg}$ and from 270.6 to $339.6 \mu \mathrm{g} / \mathrm{kg}$, respectively. The average DON content was 287.37 and $311.4 \mu \mathrm{g} / \mathrm{kg}$, respectively (Figure 5B). Though the DON levels of these germ and meals were lower than the maximum limit based on Chinese government standard (1000 $\mu \mathrm{g} / \mathrm{kg})$ [33], the ZEN contents of these germ and meals were all higher than the maximum limit (500 $\mu \mathrm{g} / \mathrm{kg}$ ) [34], which implied that ZEN pollution was a potential hazard in corn germ and its meal. 

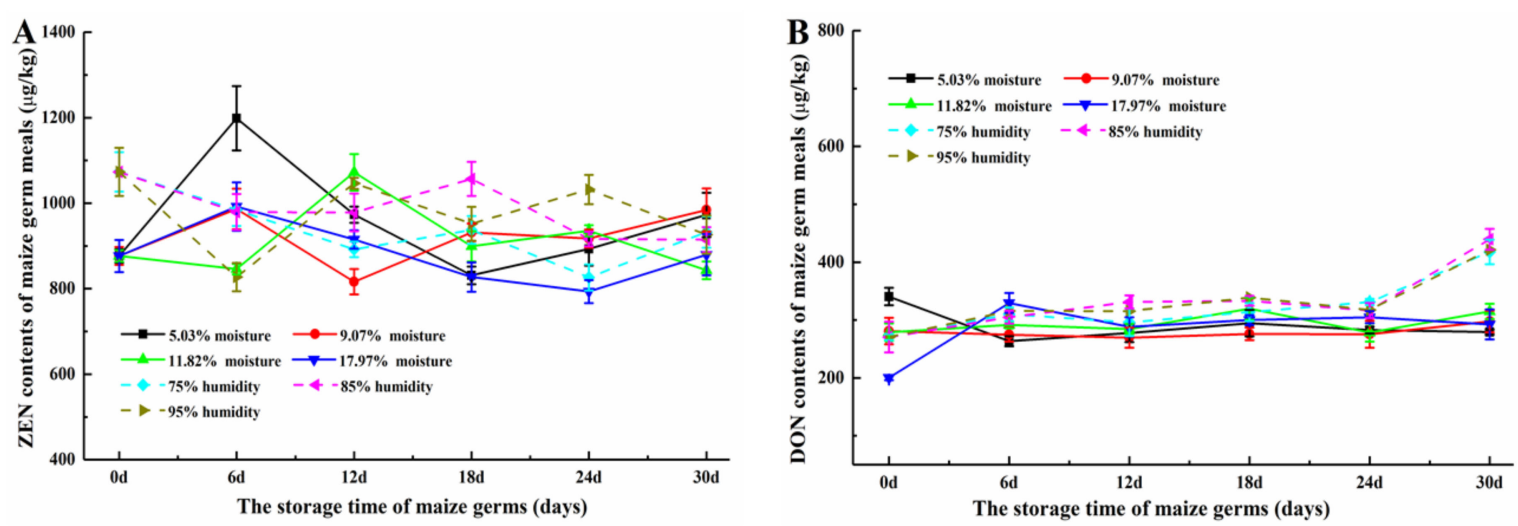

Figure 5. (A) ZEN contents and (B) DON contents of maize germ meals produced by maize germ from different storage stages. ZEN and DON contents of maize germ meals from all storage stage showed no significant difference $(p<0.05)$, respectively.

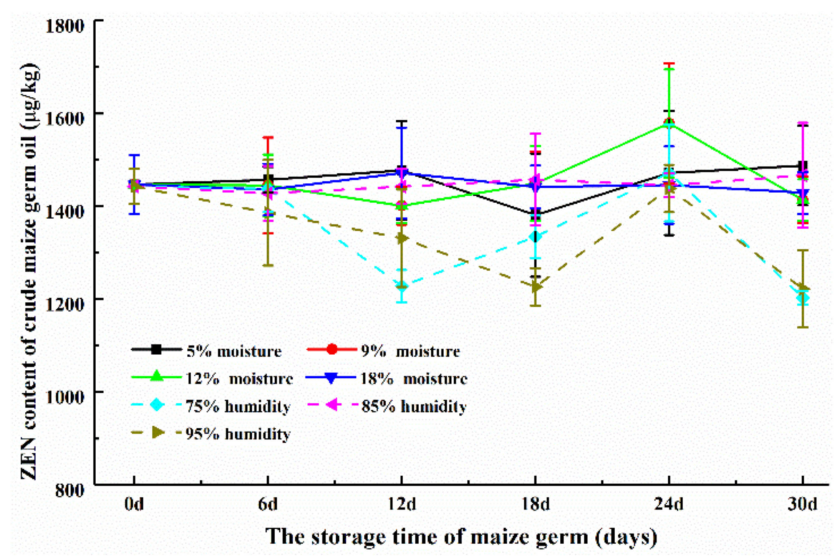

Figure 6. ZEN contents of maize germ oils extracted from the germ from different storage stages. The ZEN contents of maize germ oils from all storage stages showed no significant difference $(p<0.05)$.

As shown in Figure 6, the ZEN contents of maize germ oils extracted from germ with different initial moisture contents and stored at different humidity remained at a similar level and the ZEN contents of these samples showed the range of $1381.08-1578.63 \mu \mathrm{g} / \mathrm{kg}$ and $1203.32-1473.07 \mu \mathrm{g} / \mathrm{kg}$, respectively. The average ZEN content was 1441.40 and $1380.63 \mu \mathrm{g} / \mathrm{kg}$, respectively, which were all higher than the maximum limit $(400 \mu \mathrm{g} / \mathrm{kg}$ ) of corn germ oil [12]. However, the DON contents of all these oil samples were lower than the detection limit of HPLC method $(10 \mu \mathrm{g} / \mathrm{kg})$. The possible reason was that the DON showing low contents in germ $(153.5-489.5 \mu \mathrm{g} / \mathrm{kg})$ mostly transferred into the germ meals at the similar DON levels to germ $(240.2-439.6 \mu \mathrm{g} / \mathrm{kg})$, as DON is much easier to dissolve in the high polarity solvents such as water and acetonitrile than in the low polarity solvents such as oil and hexane [3]. Thirty crude corn oils and 40 refined corn oils were analyzed of DON. Only 20\% of crude corn oils and $12.5 \%$ of refined corn oils were found of DON with the range of $67.5-340.5 \mu \mathrm{g} / \mathrm{kg}$ and $57.1-207.5 \mu \mathrm{g} / \mathrm{kg}$, respectively [3]. Vegetable oils has a low incidence of DON, which may be related to the high water-solubility of DON. However, $25 \%$ of maize germ and $32 \%$ of corn oil samples were positive for ZEN, which may be related to its lipophilic nature [6,35].

\subsubsection{Distribution of ZEN and DON in Maize Germ and Its Processing Products}

As shown in Figure 4A, the contents of ZEN in all maize germ samples in this study showed the range of $973.32-1335.68 \mu \mathrm{g} / \mathrm{kg}$. Meanwhile, the contents of ZEN in all germ oils (Figure 5A) and all meals (Figure 6) ranged from 1203.32 to $1578.63 \mu \mathrm{g} / \mathrm{kg}$ and from 793.28 to $1198.73 \mu \mathrm{g} / \mathrm{kg}$, respectively. The average content of ZEN in maize germ, germ oils and meals were $1074.46,1421.82$ and $938.98 \mu \mathrm{g} / \mathrm{kg}$, 
respectively. Figures $4 \mathrm{~B}$ and $5 \mathrm{~B}$ show the contents of $\mathrm{DON}$ in maize germ and meals, ranging from 148.3 to $489.5 \mu \mathrm{g} / \mathrm{kg}$ and from 200.0 to $439.6 \mu \mathrm{g} / \mathrm{kg}$, respectively. The average content of DON was 258.22 and $305.04 \mu \mathrm{g} / \mathrm{kg}$, respectively. While, DON was not found in maize germ oils (Table 1). The contents of ZEN in germ oils were 1.18-1.24 times higher than the contents of ZEN in germ. While the ZEN contents in meals were about $82-90 \%$ of that in germ. Vegetable oils do not retain polar mycotoxins, whereas ZEN with less polar can accumulate in vegetable oils [6,36]. It was inferred that the ZEN was inclined to be transferred into oil, while DON was inclined to be transferred into meal during the oil extraction from maize germ, implying that the maize germ oil could have a high risk of ZEN contamination and the meal could have a high risk of DON contamination [3].

Table 1. DON contents of maize germ oils extracted from germ from different storage stages.

\begin{tabular}{ccccccc}
\hline $\begin{array}{c}\text { Days } \\
\text { No. }\end{array}$ & $\mathbf{0 ~ d}$ & $\mathbf{6} \mathbf{d}$ & $\mathbf{1 2} \mathbf{d}$ & $\mathbf{1 8} \mathbf{d}$ & $\mathbf{2 4} \mathbf{d}$ & $\mathbf{3 0 ~ d}$ \\
\hline No. 1 & ND & ND & ND & ND & ND & ND \\
No. 2 & ND & ND & ND & ND & ND & ND \\
No. 3 & ND & ND & ND & ND & ND & ND \\
No. 4 & ND & ND & ND & ND & ND & ND \\
No. 5 & ND & ND & ND & ND & ND & ND \\
No. 6 & ND & ND & ND & ND & ND & ND \\
No. 7 & ND & ND & ND & ND & ND & ND \\
\hline
\end{tabular}

No. 1-No. 4-moisture content of 5, 9, 12 and 18\%, respectively. No. 5-No. 7-environmental humidity of 75, 85 and $95 \%$, respectively. "ND" - not detected.

\section{Conclusions}

Maize germ was stored with different initial moisture contents or at different relative humidity for 30 days. The stored maize germ and their corresponding germ oils and meals were analyzed of their qualities, DON and ZEN levels. The maize germ obtained from high initial moistures or humidity condition, and their corresponding germ oils showed great changes in qualities at the end of storage. However, the ZEN and DON contents of these maize germ remained at similar levels during the storage, respectively. At the same time, their germ oils and meals also showed the same situation on the ZEN and DON levels. Therefore, the appearance of maize germ was only used for the estimation of fungal contamination of germ, but was not suitable for reflecting the levels of DON and ZEN in maize germ and its germ oil. For obtaining high quality maize germ as used in this study, it was better to keep the maize germ with low initial moisture content $(<9 \%)$ and at low relative humidity $(<75 \%)$.

\section{Materials and Methods}

\subsection{Materials}

Acetonitrile and methanol (HPLC grade) were obtained from Merck (Darmstadt, Germany). ZEN and DON standards were procured from Sigma-Aldrich (Saint Quentin-Fallavier, France). The concentrations of ZEN stock solution and DON stock solution were 0.1 and $0.5 \mathrm{mg} / \mathrm{mL}$, respectively. Then the stock solutions of ZEN and DON were diluted with acetonitrile and methanol, respectively, to obtain the working solutions. Both stock solutions and working solutions were kept at $-20{ }^{\circ} \mathrm{C}$ until used. Immunoaffinity columns of ZEN and DON were purchased from Welchrom ${ }^{\circledR}$ (Welch, Shanghai, China). All the other reagents used were of analytical grade.

\subsection{Storage of Maize Germ}

The moisture content of raw maize germ was adjusted into 5.03,9.07, 11.82 and $17.97 \%$, respectively and named as Samples 1-4. These samples were contained in open container plastic bottles which were then placed in a constant temperature and humidity incubator under the conditions of the temperature at $25^{\circ} \mathrm{C}$ and the relative humidity at $45 \%$ for 30 days storage. Other samples of $9.07 \%$ moisture content 
were used and divided into 3 groups which were kept in the open plastic bottle containers under the conditions of $25^{\circ} \mathrm{C}$ (temperature)/75\% (humidity), $25{ }^{\circ} \mathrm{C} / 85 \%$ and $25^{\circ} \mathrm{C} / 95 \%$ for $30 \mathrm{~d}$, respectively. These three samples were named as Samples 5-7. Each of these 7 samples used for the storage weighed $1200 \mathrm{~g}$. The dispersity and moldy degree of maize germ was observed during the period. After mixed thoroughly, $200 \mathrm{~g}$ maize germ was sampled from each group at 0, 6, 12, 18, 24 and 30 days. Then the moisture contents and crude fat contents of maize germ were determined according to the requirements of Chinese government standards.

\subsection{Quality Parameters of Stored Maize Germ}

\subsubsection{Moisture Content}

The determination of moisture content referring to GB5009.3-2016 [37] is briefly described below. The clean aluminum weighing bottle was placed in a drying cabinet at $101-105^{\circ} \mathrm{C}$ and heated for one hour. Then, the weighing bottle was placed in a desiccator for cooling. The above operation was repeated until the mass change of the weighing bottle did not exceed $2 \mathrm{mg}$. About $5 \mathrm{~g}$ of sample was grounded and weighted in the weighing bottle and then placed in the drying cabinet at $101-105{ }^{\circ} \mathrm{C}$ for two hours. After the cooling in a desiccator, the sample was weighed. Then, the sample was heated repeatedly until the mass change of the weighing bottle did not exceed $2 \mathrm{mg}$. The moisture content of sample was calculated according to the value difference.

\subsubsection{Crude Fat Content}

The conventional Soxhlet extraction (SE) was selected for the determination of crude fat content according to previous report [38]. The sample was extracted for $8 \mathrm{~h}$ using diethyl ether at $60^{\circ} \mathrm{C}$. The small amount of diethyl ether remaining in the receiving bottle was removed in an drying cabinet at $101-105^{\circ} \mathrm{C}$ for one hour.

\subsection{Preparation of Maize Germ Oil and Meal}

The stored maize germ sample was crushed and sieved though a 20-mesh sieve. Smashed maize germ and n-hexane were mixed in a sealed container. The container was put into a water bath $\left(50{ }^{\circ} \mathrm{C}\right)$ and stirred for $8 \mathrm{~h}$. Then, the mixture was filtered through a Buchner funnel under vacuum and the filtrate was collected. The maize germ oil was gained by removing the solvent from the filtrate by the vacuum rotary evaporator. The maize germ meal was obtained after removing $\mathrm{n}$-hexane from the filter residue. Then, the quality parameters (color, acid value and peroxide value) of maize germ oil were detected.

\subsection{Quality Parameters of Maize Germ Oil}

\subsubsection{Color}

The color of maize germ oil was detected according to GB22460-2008 [39]. The mothed was briefly described as below. A certain amount of maize germ oil was injected into the $25.4 \mathrm{~mm}$ colorimetric tank. The liquid level of oil was about $5 \mathrm{~mm}$ away from the upper opening of the colorimetric tank. Then, the colorimetric tank was placed into Lovibond Tintometer (Perkone Technology Co., Ltd., Hangzhou, China). In order to compare the color difference of oil sample, the yellow value was set as 30. The red value was adjusted until the color of the shade guide was approximately same as the color of oil sample.

\subsubsection{Acid Value}

The determination of acid value in maize germ oil was carried out using the national standard GB/T 5009.229-2016 [40]. The main operational procedure was conducted as follows: About $2 \mathrm{~g}$ of oil sample was dissolved in $25 \mathrm{~mL}$ mixed solvent (ether:isopropanol $=1: 1, v / v$ ). The mixture was shaken well, 
and three drops of phenolphthalein indicator were added to the mixed solution and then titrated with potassium hydroxide standard solution $(0.1000 \mathrm{~mol} / \mathrm{L})$. The acid value was subsequently calculated.

\subsubsection{Peroxide Value}

The peroxide value of maize germ oil was determined based on the method as described before [41]. Briefly, about $2 \mathrm{~g}$ maize germ oil was added in an iodine flask and then $30 \mathrm{~mL}$ mixed solvent (chloroform:acetic acid $=3: 2, v / v$ ) and $1 \mathrm{~mL}$ saturated potassium iodide solution were added orderly. The mixed solution was shaken and placed in the dark for reaction ( $5 \mathrm{~min})$. After the reaction, $100 \mathrm{~mL}$ of distilled water and three drops of starch indicator were added and followed by titrating with the $\mathrm{Na}_{2} \mathrm{~S}_{2} \mathrm{O}_{3}$-solution.

\subsection{Mycotoxin Levels in Maize Germ and Its Processing Products}

\subsubsection{ZEN Levels of Maize Germ and Its Processing Products}

The ZEN levels of the samples were detected by the method as described before with slight modification [9,42]. Briefly, a 5-g sample was mixed with $25 \mathrm{~mL}$ acetonitrile-deionized water $(8: 2$, $v / v$ ) as well as $1.0 \mathrm{~g}$ sodium chloride. Then the mixture was homogenized by a homogenizer (FM200, FLUKO ${ }^{\circledR}$, Shanghai, China) and centrifuged at $7000 \times g$ for $3 \mathrm{~min}$. After filtrated with glass-fiber filter paper, the filtrate was slowly passed through a ZEN immunoaffinity column and followed by PBS solution, deionized water and flushing air. The methanol was added into the column to elution the sample. The solution was collected, dried and then dissolved with acetonitrile, and finally filtered through a $0.22-\mu \mathrm{m}$ syringe for the analysis of ZEN by HPLC method.

The HPLC (Waters 2695, Waters Corp., Milford, MA, USA) equipped with Waters 2495 fluorescence detector (FI) was used to analyze sample. The sample was separated by a SunFire ${ }^{\circledR} \mathrm{C} 18$ column $\left(4.6 \times 150 \mathrm{~mm}, 5 \mu \mathrm{m}\right.$, Waters, Wexford, Ireland), which was located in a column oven set at $35^{\circ} \mathrm{C}$. The eluent was consisted of acetonitrile and water $(55: 45, v / v)$ with a speed rate of $1.0 \mathrm{~mL} / \mathrm{min}$. The injection volume was $20 \mu \mathrm{L}$. The excitation wavelength was set at $278 \mathrm{~nm}$ and the emission wavelength was set at $462 \mathrm{~nm}$.

\subsubsection{DON Levels of Maize Germ and Its Processing Products}

The DON levels of the samples were determined by the following method described previously with some modifications [3,8,43]. In brief, a 12.5-g sample was mixed with $100 \mathrm{~mL}$ deionized water and $5 \mathrm{~g}$ polyethylene glycol 8000 . After sufficient homogenization, the mixture was centrifuged and filtrated with glass-fiber filter paper. Then, the filtrate was passed through a DON immunoaffinity column at a low speed rate. A certain amount of air was passed through the column to exclude the residual liquid. Subsequently, the column was washed with PBS solution, deionized water and flushing air. Finally, the elution was completed with methanol. The eluent was dried under a gentle stream of $\mathrm{N}_{2}$. After dissolving with solution (methanol:deionized water $=20: 80, v / v$ ), the sample was filtered through a $0.22-\mu \mathrm{m}$ syringe and used for instrument analysis.

The HPLC equipped with Waters 2489 ultraviolet detector (UV) was used for the analysis of DON content. A SunFire ${ }^{\circledR} \mathrm{C} 18$ column $(4.6 \times 250 \mathrm{~mm}, 5 \mu \mathrm{m}$, Waters, Ireland $)$ coupled with a SunFire ${ }^{\circledR}$ guard column ( $5 \mu \mathrm{m}$, Waters, Ireland) was used to separate sample at $35^{\circ} \mathrm{C}$ with a flow rate of $0.25-\mathrm{mL} / \mathrm{min}$ and a $50-\mu \mathrm{L}$ injection volume. The elution process was performed with methanol and water $(20: 80, v / v)$ and the detection wavelength was set at $218 \mathrm{~nm}$.

\subsection{Statistical Analysis}

The statistical analysis was performed using the Waters-Empower 3 software (Waters Crop., Milford, MA, USA) and SPSS 22.0 (IBM Corporation, Armonk, New York, USA). Figures were drawn with Origin 8 (Origin Lab, Northampton, MA, USA). All experiments were carried out in triplicate, 
and data were expressed as mean \pm standard deviation. The mean values were compared with one-way ANOVA, followed by Dunnett's test and the $p<0.05$ stood for significant difference.

Supplementary Materials: The following are available online at http://www.mdpi.com/2072-6651/12/9/535/s1, Figure S1: The appearances of maize germ during the 30-day storage with different initial moisture contents, Figure S2: The appearances of maize germ during the 30-day storage at different relatively humidity.

Author Contributions: Conceptualization, Y.-q.W. and X.-m.J.; methodology, L.-1.X.; software, Y.-q.W.; validation, Y.-q.W. and L.-1.X.; formal analysis, Y.-q.W.; investigation, Y.-q.W.; resources, L.-1.X.; data curation, L.-1.X.; writing —original draft preparation, Y.-q.W.; writing — review and editing, X.-m.J.; visualization, L.-l.X.; supervision, C.-h.X. and X.-m.J.; project administration, C.-h.X.; funding acquisition, C.-h.X. All authors have read and agreed to the published version of the manuscript.

Funding: This work was supported by grants from the National Key R\&D Program of China (Grant No. 2018YFC0311206).

Conflicts of Interest: The authors declare no conflict of interest.

\section{References}

1. Chulze, S.N. Strategies to reduce mycotoxin levels in maize during storage: A review. Food Addit. Contam. Part A 2010, 27, 651-657. [CrossRef] [PubMed]

2. Bhat, R.; Reddy, K.R.N. Challenges and issues concerning mycotoxins contamination in oil seeds and their edible oils: Updates from last decade. Food Chem. 2017, 215, 425-437. [CrossRef] [PubMed]

3. Xu, L.-L.; Wen, Y.-Q.; Liu, Y.-L.; Ma, Y.-X. Occurrence of deoxynivalenol in maize germs from North China Plain and the distribution of deoxynivalenol in the processed products of maize germs. Food Chem. 2018, 266, 557-562. [CrossRef] [PubMed]

4. Setyabudi, F.; Nuryono, N.; Wedhastri, S.; Mayer, H.K.; Razzazi-Fazeli, E. Limited survey of deoxynivalenol occurrence in maize kernels and maize-products collected from Indonesian retail market. Food Control. 2012, 24, 123-127. [CrossRef]

5. Aniołowska, M.; Steininger, M. Determination of trichothecenes and zearalenone in different corn (Zea mays) cultivars for human consumption in Poland. J. Food Compos. Anal. 2014, 33, 14-19. [CrossRef]

6. Escobar, J.; Lorán, S.; Giménez, I.; Ferruz, E.; Herrera, M.; Herrera, A.; Ariño, A. Occurrence and exposure assessment of Fusarium mycotoxins in maize germ, refined corn oil and margarine. Food Chem. Toxicol. 2013, 62, 514-520. [CrossRef]

7. Neme, K.; Mohammed, A. Mycotoxin occurrence in grains and the role of postharvest management as a mitigation strategies. A review. Food Control. 2017, 78, 412-425. [CrossRef]

8. Li, R.; Wang, X.; Zhou, T.; Yang, D.; Wang, Q.; Zhou, Y. Occurrence of four mycotoxins in cereal and oil products in Yangtze Delta region of China and their food safety risks. Food Control. 2014, 35, 117-122. [CrossRef]

9. Drzymala, S.S.; Weiz, S.; Heinze, J.; Marten, S.; Prinz, C.; Zimathies, A.; Garbe, L.-A.; Koch, M. Automated solid-phase extraction coupled online with HPLC-FLD for the quantification of zearalenone in edible oil. Anal. Bioanal. Chem. 2015, 407, 3489-3497. [CrossRef]

10. Bao, L.; Oles, C.J.; White, K.D.; Sapp, C.; Trucksess, M.W. Use of a multifunctional column for the determination of deoxynivalenol in grains, grain products, and processed foods. J. AOAC Int. 2011, 94, 1506-1512. [CrossRef]

11. Wan, J.; Chen, B.; Rao, J. Occurrence and preventive strategies to control mycotoxins in cereal-based food. Compr. Rev. Food Sci. Food Saf. 2020, 19, 928-953. [CrossRef]

12. Commission Regulation (EC). No. 1126/2007 of 28 September 2007 amending regulation (EC) No. 1881/2006 setting maximum levels for certain contaminants in foodstuffs as regards Fusarium toxins in maize and maize products. OJEU 2007, L255, 14-17.

13. De Boevre, M.; Di Mavungu, J.D.; Landschoot, S.; Audenaert, K.; Eeckhout, M.; Maene, P.; Haesaert, G.; De Saeger, S. Natural occurrence of mycotoxins and their masked forms in food and feed products. World Mycotoxin J. 2012, 5, 207-219. [CrossRef]

14. Brera, C.; Catano, C.; De Santis, B.; Debegnach, F.; De Giacomo, M.; Pannunzi, E.; Miraglia, M. Effect of Industrial Processing on the Distribution of Aflatoxins and Zearalenone in Corn-Milling Fractions. J. Agric. Food Chem. 2006, 54, 5014-5019. [CrossRef] 
15. Schaafsma, A.W.; Frégeau-Reid, J.; Phibbs, T. Distribution of deoxynivalenol in Gibberella-infected food-grade corn kernels. Can. J. Plant Sci. 2004, 84, 909-913. [CrossRef]

16. Park, J.; Kim, D.-H.; Moon, J.-Y.; An, J.-A.; Kim, Y.-W.; Chung, S.H.; Lee, C. Distribution Analysis of Twelve Mycotoxins in Corn and Corn-Derived Products by LC-MS/MS to Evaluate the Carry-Over Ratio during Wet-Milling. Toxins 2018, 10, 319. [CrossRef]

17. Mannaa, M.; Kim, K.D. Influence of Temperature and Water Activity on Deleterious Fungi and Mycotoxin Production during Grain Storage. Mycobiology 2017, 45, 240-254. [CrossRef]

18. Zhao, X.; Wang, W.; Chu, X.; Li, C.; Kimuli, D. Early Detection of Aspergillus parasiticus Infection in Maize Kernels Using Near-Infrared Hyperspectral Imaging and Multivariate Data Analysis. Appl. Sci. 2017, 7, 90. [CrossRef]

19. Dickey, L.; Kurantz, M.J.; Parris, N. Oil separation from wet-milled corn germ dispersions by aqueous oil extraction and aqueous enzymatic oil extraction. Ind. Crop. Prod. 2008, 27, 303-307. [CrossRef]

20. Karlovic, D.; Sovilj, M.; Turkulov, J. Kinetics of oil extraction from corn germ. J. Am. Oil Chem. Soc. 1992, 69, 471-476. [CrossRef]

21. Moreau, R.; Johnston, D.B.; Hicks, K.B. The influence of moisture content and cooking on the screw pressing and prepressing of corn oil from corn germ. J. Am. Oil Chem. Soc. 2005, 82, 851-854. [CrossRef]

22. Ni, S.; Zhao, W.; Zhang, Y.; Gasmalla, M.A.A.; Yang, R. Efficient and eco-friendly extraction of corn germ oil using aqueous ethanol solution assisted by steam explosion. J. Food Sci. Technol. 2016, 53, 2108-2116. [CrossRef] [PubMed]

23. Stokoe, W.N. The rancidity of coconut oil produced by mould action1. Biochem. J. 1928, 22, 80-93. [CrossRef] [PubMed]

24. Wang, H.; Wang, T.; Johnson, L.A. Effects of Kernel Breakage and Fermentation on Corn Germ Integrity and Oil Quality. J. Agric. Food Chem. 2010, 58, 10039-10044. [CrossRef] [PubMed]

25. Abdulkarim, S.; Long, K.; Lai, O.-M.; Muhammad, K.; Ghazali, H. Frying quality and stability of high-oleic Moringa oleifera seed oil in comparison with other vegetable oils. Food Chem. 2007, 105, 1382-1389. [CrossRef]

26. Vu, T.P.; He, L.; McClements, D.J.; A Decker, E. Effects of water activity, sugars, and proteins on lipid oxidative stability of low moisture model crackers. Food Res. Int. 2020, 130, 108844. [CrossRef]

27. Zheng, L.; Ji, C.; Jin, J.; Xie, D.; Liu, R.; Wang, X.; Jin, Q.; Huang, J. Effect of Moisture and Heat Treatment of Corn Germ on Oil Quality. J. Am. Oil Chem. Soc. 2018, 95, 383-390. [CrossRef]

28. Winkler-Moser, J.K.; Breyer, L. Composition and oxidative stability of crude oil extracts of corn germ and distillers grains. Ind. Crop. Prod. 2011, 33, 572-578. [CrossRef]

29. Adetunji, M.C.; Atanda, O.; Ezekiel, C.N.; Sulyok, M.; Warth, B.; Beltrán, E.; Krska, R.; Obadina, O.; Bakare, A.; Chilaka, C. Fungal and bacterial metabolites of stored maize (Zea mays, L.) from five agro-ecological zones of Nigeria. Mycotoxin Res. 2014, 30, 89-102. [CrossRef]

30. Danso, J.; Osekre, E.; Opit, G.; Arthur, F.; Campbell, J.; Mbata, G.; Manu, N.; Armstrong, P.; McNeill, S. Impact of storage structures on moisture content, insect pests and mycotoxin levels of maize in Ghana. J. Stored Prod. Res. 2019, 81, 114-120. [CrossRef]

31. Gagiu, V.; Mateescu, E.; Armeanu, I.; Dobre, A.A.; Smeu, I.; Cucu, M.E.; Oprea, O.A.; Iorga, E.; Belc, N. Post-Harvest Contamination with Mycotoxins in the Context of the Geographic and Agroclimatic Conditions in Romania. Toxins 2018, 10, 533. [CrossRef] [PubMed]

32. Koskei, P.; Bii, C.C.; Musotsi, P.; Karanja, S.M. Postharvest Storage Practices of Maize in Rift Valley and Lower Eastern Regions of Kenya: A Cross-Sectional Study. Int. J. Microbiol. 2020, 2020, 6109214. [CrossRef] [PubMed]

33. Committee C.N.S. Limits of Mycotoxins in Food. Gb 2761-2011; China National Standardization Committee: Beijing, China, 2011. (In Chinese)

34. Committee C.N.S. Feed Hygiene Standards. GB 13078-2017; China National Standardization Committee: Beijing, China, 2017. (In Chinese)

35. Schollenberger, M.; Müller, H.-M.; Rüfle, M.; Drochner, W. Natural occurrence of 16 Fusarium toxins in edible oil marketed in Germany. Food Control. 2008, 19, 475-482. [CrossRef]

36. Mahoney, N.; Molyneux, R.J. Rapid Analytical Method for the Determination of Aflatoxins in Plant-Derived Dietary Supplement and Cosmetic Oils. J. Agric. Food Chem. 2010, 58, 4065-4070. [CrossRef]

37. Committee C.N.S. Determination of Moisture Content in Food. GB 5009.3-2016; China National Standardization Committee: Beijing, China, 2016. (In Chinese) 
38. Zheng, L.; Zhang, T.; Xie, L.; Karrar, E.; Shi, L.; Jin, J.; Wang, X.; Jin, Q. Physicochemical characteristics of Actinostemma lobatum Maxim. kernel oil by supercritical fluid extraction and conventional methods. Ind. Crop. Prod. 2020, 152, 112516. [CrossRef]

39. Committee C.N.S. Determination of Lovibond Color of Animal and Vegetable Oils. GB/T 22460-2008; China National Standardization Committee: Beijing, China, 2008. (In Chinese)

40. Committee C.N.S. Determination of Acid Value in Food. GB 5009.229-2016; China National Standardization Committee: Beijing, China, 2016. (In Chinese)

41. Wen, Y.-Q.; Xue, C.-H.; Xu, L.-L.; Wang, X.-H.; Bi, S.-J.; Xue, Q.-Q.; Zhang, T.; Xue, Y.; Li, Z.-J.; Chen, G.-D.; et al. Application of Plackett-Burman Design in Screening of Natural Antioxidants Suitable for Anchovy Oil. Antioxidants 2019, 8, 627. [CrossRef]

42. Committee C.N.S. Determination of Zearalenone in Food. GB 5009.209-2016; China National Standardization Committee: Beijing, China, 2016. (In Chinese)

43. Committee C.N.S. Determination of Deoxynivalenol and its Acetylated Derivatives in Food. GB 5009.111-2016; China National Standardization Committee: Beijing, China, 2016. (In Chinese)

(C) 2020 by the authors. Licensee MDPI, Basel, Switzerland. This article is an open access article distributed under the terms and conditions of the Creative Commons Attribution (CC BY) license (http://creativecommons.org/licenses/by/4.0/). 